\title{
GESTÃO DA INOVAÇÃO: UM RELATO DA EXPERIÊNCIA NO NÚCLEO DE INOVAÇÃO TECNOLÓGICA DA UEPB
}

\author{
INNOVATION MANAGEMENT: A REPORT ON THE EXPERIENCE AT THE \\ TECHNOLOGICAL INNOVATION CENTER OF UEPB
}

Yedda Alexandra Freire de Albuquerque Prazeres Mestre pelo PROFNIT/IFPB. Assistente Técnico - UEPB.

Campina Grande, Paraíba, Brasil. yedda@ servidor.uepb.edu.br

Simone Silva dos Santos Lopes Doutora em Genética - UFMG Docente da Universidade Estadual da Paraíba - UEPB. Campina Grande, Paraíba, Brasil. simonelopes@servidor.uepb.edu.br

Resumo: Este artigo apresenta um relato acerca da gestão da inovação do Núcleo de Inovação Tecnológica da UEPB (Universidade Estadual da Paraíba). O objetivo do estudo foi descrever as atividades realizadas pelo Núcleo de Inovação Tecnológica (NIT) da UEPB, identificando seu perfil institucional com base no Novo Marco Legal da Ciência, Tecnologia e Inovação (Lei no 13.243/2016), a fim de contribuir com informações para NITs estaduais em processo de consolidação. Para atender o objetivo do estudo, foi realizado um levantamento de dados a respeito da estruturação e regulamentação do NIT da UEPB. Estes dados foram obtidos através de consultas aos documentos e legislações da universidade e, também, através de informações disponíveis no site da instituição, além da própria vivência em atividades técnicas e administrativas desenvolvidas pelas autoras deste artigo, que atuam no NIT. Após análise dos documentos, constatou-se que o NIT da UEPB atua em todas as funções estabelecidas no Novo Marco Legal da Ciência, Tecnologia e Inovação. Assumindo assim o perfil administrativo, o perfil legal e o perfil de negócios. Com isso, infere-se que, para uma atuação mais efetiva e eficaz na gestão da inovação, é necessário agregar conhecimentos multidisciplinares.

Palavras-Chave: Marco legal. NIT. Inovação tecnológica. Gestão.

Abstract: This article presents an account about the innovation management of the UEPB (Universidade Estadual da Paraíba) Technological Innovation Center (NIT). The objective of the study was to describe the activities carried out by the UEPB Technological Innovation Center, identifying its institutional profile based on the New Legal Framework for Science, Technology and Innovation (Law $\mathrm{n}^{\circ}$. 13.243/2016). To meet the objective of the study, a survey of data was carried out on the structuring and regulation of the UEPB NIT. These data were obtained through consultations in the university's documents and legislation, and also through information available on the institution's website, in addition to the experience in technical and administrative activities developed by the authors of this article, who work at the NIT. After analyzing the documents, it was found that the UEPB NIT acts in all the functions established in the New Legal Framework for Science, Technology and Innovation. Thus assuming the administrative profile, the legal profile and the business profile. Thus, it is inferred that, for a more effective and efficient performance in the management of innovation, it is necessary to add multidisciplinary knowledge.

Keywords: Legal framework. NIT. Technological innovation. Management.

Cite como

American Psychological Association (APA)

Prazeres, Y. A. F. A., \& Lopes, S. S. S. (2021, jul./dez.). Gestão da inovação: um relato da experiência no Núcleo de Inovação Tecnológica da UEPB. Revista Inovação, Projetos e Tecnologias - IPTEC, São Paulo, 9(2), 255270. https://doi.org/10.5585/iptec.v9i2.20173. 


\section{Introdução}

A inovação e o desenvolvimento tecnológico têm papel cada vez mais relevante no desenvolvimento socioeconômico do país. A incorporação da inovação e do desenvolvimento tecnológico tem sido peças-chave na busca e sustentação de vantagens competitivas de indústrias e setores econômicos (Pires, Rita, \& Pires, 2020). Os dados mais recentes do Índice Global de Inovação (IGI), que mede o desempenho dos ecossistemas da inovação de 132 economias, demonstraram que as principais economias que registraram os melhores desempenhos em inovação de forma consistente estão entre aquelas com melhor Índice de Desenvolvimento Humano (IDH).

A relevância do papel da inovação foi percebida pelo Estado Brasileiro, mais precisamente, a partir da década de 1990, quando o governo brasileiro passou a enfatizar a necessidade de estruturar iniciativas explícitas de estímulo à incorporação da Ciência, Tecnologia e Inovação (CT\&I) (Lotufo, 2009). Neste cenário de fortalecimento do Sistema Nacional de Inovação, foi regulamentada a Lei de Inovação n ${ }^{\circ}$ 10.973/2004, que posteriormente sofreu alterações através da Lei no 13.243/2016, que ficou conhecida como o "Novo Marco Legal da Ciência, Tecnologia e Inovação". Esse ordenamento jurídico estimula que o conhecimento gerado nas Instituições de Ciência e Tecnologia (ICT) possa alavancar economicamente o setor industrial e a sociedade (Velho, Campagnolo, \& Dubeux, 2019).

Assim, para valorizar e estimular as produções científicas e tecnológicas, a Lei de Inovação trouxe, em seu arcabouço legal, a obrigatoriedade da criação dos Núcleos de Inovação Tecnológica (NITs) nas Instituições Científicas e Tecnológicas (ICTs). Os Núcleos de Inovação Tecnológica (NITs) foram criados com o objetivo de aproximar a ICT do ambiente produtivo a fim de propagar os resultados do conhecimento gerado dentro das ICTs.

Diante dessa determinação legal, a Universidade Estadual da Paraíba (UEPB) criou, em março de 2009, o Núcleo de Inovação e Transferência Tecnológica - NITT/UEPB que tinha como principal objetivo fazer a gestão da política de inovação da instituição. A escolha do NIT da UEPB como objeto de estudo se deu porque, além da UEPB ter uma excelência acadêmica reconhecida e consolidada no Estado, a referida instituição ganhou destaque no ano de 2020, ao figurar no ranking de produção de patentes como uma das principais depositantes em pedidos de patente junto ao Instituto Nacional de Propriedade Industrial (INPI). Ademais, o estudo tratase de um relato de experiência, o qual só foi possível ser realizado, porque as autoras deste artigo atuam no NIT da UEPB. 
Desta forma, o objetivo deste estudo consistiu em descrever as atividades realizadas pelo Núcleo de Inovação Tecnológica da UEPB, identificando seu perfil institucional com base no Novo Marco Legal da Ciência, Tecnologia e Inovação (Lei nº 13.243/2016), para contribuir com outros NITs estaduais para sua implantação e consolidação.

Assim, este relato técnico analisou desde a institucionalização do Núcleo de Inovação Tecnológica da UEPB, perpassando por toda a dinâmica que envolveu essa institucionalização até a apresentação dos resultados da gestão e finalmente a identificação do perfil institucional do NIT-UEPB. Os dados, retratados no presente relato técnico, têm relevância legitimada uma vez que apresentam a experiência da gestão da inovação na UEPB que podem servir como guia para iniciativas em outras instituições, além de auxiliar na identificação de possíveis gargalos para melhoria da gestão do próprio NIT-UEPB.

\section{Referencial teórico}

\subsection{Gestão da inovação e o marco legal da ciência, tecnologia e inovação}

O desenvolvimento socioeconômico de um país tem relação direta com a inovação e o seu avanço tecnológico. Entretanto, embora a importância da inovação para o desenvolvimento socioeconômico seja cada vez mais reconhecida, o seu gerenciamento ainda é um desafio para muitas instituições. Para conseguir êxito no processo de inovar, faz-se necessário adotar modelos e práticas de gestão adequados e não apenas escolher as melhores técnicas ou aportar os melhores recursos (Toledo, 2015).

Para Lopes, Teles, Silva \& Lopes (2020), nos dias atuais, a inovação possui caráter estratégico, pois estabelece uma nova dinâmica nas organizações, gerando a necessidade de aquisição de novas tecnologias, novos processos e novos modelos de gestão. Tidd, Bessant \& Pavitt (2015) destacam que gestão da inovação é a gestão integrada de alternativas lucrativas a partir de conhecimento, informação e criatividade. Gavira, Ferro, Rohrich \& Quadros (2007) definem a gestão da inovação como um conjunto de práticas, conceitos e ferramentas que ajuda o tomador de decisão no processo de geração de inovações.

Melo, Rita, Ferreira, Tonholo \& Oliveira Sá (2020) ressaltam que existem muitas metodologias de gestão da inovação na literatura. Contudo, faz-se necessário encontrar quais as ferramentas e métodos são mais compatíveis com a cultura da instituição (CNI, 2010). Nesse sentido, entendendo que existem diferenciados contextos, não existe uma única forma de gerenciar a inovação, cada instituição deverá buscar a solução adequada de acordo com suas necessidades, recursos e estratégias. 
Nesse contexto, as universidades têm se estruturado e desenvolvido novas competências em gestão. Observa-se a criação de vários mecanismos organizacionais que têm como principal objetivo realizar a gestão da inovação dentro da instituição. Mas, para que essa inovação seja concebível, é necessária uma maior aproximação entre Estado, empresas e ICT. Lopes et al. (2020) destacam que o modelo de inovação com base na relação governo-universidadeindústria tem sido visto como fundamental para o desenvolvimento da inovação. Dessa forma, a institucionalização de políticas e instrumentos de incentivo à pesquisa, à inovação e à interação entre ICT e empresas torna-se cada vez mais relevante.

De acordo com Ferreira (2018), a transferência de tecnologia universitária e sua estruturação não são atividades recentes, o autor revela que foram verificadas adoções de políticas de propriedade intelectual desde o início do século XX. Toledo (2015) destaca que, na década de 1920, a Universidade de Wisconsin foi a pioneira em ações de propriedade intelectual e licenciamento de tecnologias. A autora ressalta ainda as atividades do MIT - Massachusetts Institute of Technology, na década de 1930, e da Universidade de Stanford em 1950, além da criação dos Escritórios de Transferência de Tecnologia (Office of Technology Licensing) que ganharam importância com a promulgação do Bayh-Dole Act, na década de 80, uma lei amplamente reconhecida como uma das principais mudanças para a pesquisa acadêmica, que permitiu às universidades americanas patentear e licenciar, com exclusividade, invenções financiadas por fundos federais. Em seu estudo, Toledo (2015) apresenta ainda exemplos de transferência universitária em outros países como Israel, Reino Unido e Chile.

No entanto, no Brasil, a interação universidade-empresa era pouco disseminada, segundo Ferreira (2018), durante a década de 80 e 90, somente as principais universidades públicas do País possuíam em sua estrutura iniciativas com intuito de estimular sua interação com a indústria. Essa realidade começou a mudar a partir da promulgação da Lei de Inovação (Lei $\left.n^{\circ} 10.973 / 2004\right)$. Esta Lei $n^{\circ} 10.973 / 2004$ dispõe sobre incentivos à inovação e à pesquisa científica e tecnológica no ambiente produtivo e apresenta diversos mecanismos de promoção a essa interação entre a ICT e a indústria (BRASIL, 2004).

Entre os temas tratados pela Lei de Inovação, "grande peso é dado ao fortalecimento dos agentes intermediadores da interação ICT - Empresa, como os Núcleos de Inovação Tecnológica - NIT” (Rauen, 2016). Esses NITs foram estabelecidos através da lei para apoiar a gestão da Inovação nas ICT e agir como intermediador entre a ICT e as empresas.

Mas, apesar de todo benefício trazido pela Lei de Inovação, ela não foi suficiente para promover de fato essa aproximação entre a ICT e o setor produtivo, então, em janeiro de 2016, 
a Lei de Inovação passou por uma atualização, através da Lei $\mathrm{n}^{\circ} 13.243$, que foi nomeada de Novo Marco Legal da Ciência, Tecnologia e Inovação.

O Novo Marco Legal alterou a Lei de Inovação e também diversas outras legislações que se relacionavam com o tema da inovação. Além disso, conferiu aos NIT uma série de novas competências, no sentido de fortalecer o seu papel estratégico dentro da ICT. A regulamentação do Novo Marco Legal ocorreu, em fevereiro de 2018, através do Decreto $\mathrm{n}^{\circ}$ 9.283, que estabeleceu "medidas de incentivo à inovação e à pesquisa científica e tecnológica no ambiente produtivo, com vistas à capacitação tecnológica, ao alcance da autonomia tecnológica e ao desenvolvimento do sistema produtivo nacional e regional” (BRASIL, 2018).

O Novo Marco Legal trouxe avanços positivos em relação às legislações anteriores, segundo Velho (2019), as mudanças promovidas pelo Novo Marco Legal estimulam a superação de obstáculos apontados como limitadores da promoção das atividades de CT\&I no País.

\subsection{Os Núcleos de Inovação Tecnológica - NIT}

No contexto do desenvolvimento de políticas e instrumentos que pudessem fortalecer a Ciência, Tecnologia e Inovação no Brasil, foi estabelecida, através da Lei de Inovação, a obrigatoriedade de criação de Núcleo de Inovação Tecnológica para toda ICT pública. Assim, a Lei de Inovação determinou que "toda ICT pública deverá dispor de núcleo de inovação tecnológica (NIT), próprio ou em associação com outras ICT" para apoiar a gestão de sua política de inovação (BRASIL, 2004).

Os NIT são estruturas instituídas nas ICTs com a finalidade de gerenciar a política institucional de inovação (BRASIL, 2016). Para Quintella e Torres (2012), os NIT foram criados para promover um ambiente favorável a parcerias estratégicas entre as universidades, institutos tecnológicos e empresas. Lima e Sartori (2020) acrescentam que o surgimento dos NITs é um dos resultados dos esforços do Brasil para se tornar um país competitivo e inovador.

O relatório do Formulário para Informações sobre a Política de Propriedade Intelectual das Instituições Científicas, Tecnológicas e de Inovação do Brasil (FORMICT), ano base 2018, publicado pelo Ministério da Ciência, Tecnologia, Inovações e Comunicações, apresentou aumentos significativos em relação ao montante dos contratos de tecnologia, com um acréscimo de $\mathrm{R} \$ 717,6$ milhões, e o número de pedidos de proteção concedido, com o aumento de 480 pedidos deste tipo em relação ao ano-base de 2017 (BRASIL, 2019). 
Assim, a partir dessa visão, entende-se que é através da transferência de tecnologia para as empresas e a disponibilização dessas tecnologias para a sociedade que a inovação acontece. Lotufo (2009) explica que muitas tecnologias desenvolvidas nas ICT estão em estágio embrionário e necessitam de recursos e de tempo para que se transformem em inovação. Estes recursos podem ser oriundos das empresas, sendo que o NIT atua justamente nessa intermediação entre a ICT, detentora da pesquisa científica e as empresas detentoras dos recursos para transformarem esse conhecimento em inovação.

Para aproximar a universidade das empresas, a Lei de Inovação estabeleceu diversas funções para o NIT, conferiu-lhe atividades de cunho estratégico, analítico e de negócios. E assim, conforme destaca Lotufo (2009), o NIT passa a ser o interlocutor central com o setor privado e com a própria instituição, atuando para a transferência de tecnologia e para a proteção do conhecimento na ICT.

\section{Metodologia}

Este relato técnico é apresentado a partir da atuação do NIT na gestão da inovação na UEPB. Com objetivo exploratório e descritivo, o presente relato técnico foi desenvolvido por meio de um levantamento de dados acerca da estruturação e regulamentação do NIT da UEPB.

Estes dados foram obtidos através de consultas aos documentos e legislações da universidade e, também, através de informações disponíveis no site da instituição. Além da própria vivência em atividades técnicas e administrativas desenvolvidas pelas autoras deste artigo, que atuam no NIT.

Os materiais utilizados para análise foram as resoluções internas da UEPB, as atas de reuniões, os relatórios de gestão, as deliberações do Conselho Universitário - CONSUNI, as notícias disponibilizadas no sítio da ICT (https://www.uepb.edu.br/). Além disso, foi feita também a investigação das informações disponibilizadas na base de dados do Instituto Nacional de Propriedade Industrial - INPI, referente aos pedidos de proteção de propriedade intelectual que foram submetidos pela UEPB àquele órgão, como também a consulta aos dados disponíveis nos relatórios do Formulário para Informações sobre a Política de Propriedade Intelectual das Instituições Científicas, Tecnológicas e de Inovação do Brasil (FORMICT).

A partir desse compêndio de informações, foi possível identificar qual o perfil de atuação do NIT no que tange às competências estabelecidas pelo Novo Marco Legal da Ciência, Tecnologia e Inovação (Lei no 13.243/2016). 


\section{Discussão e resultados}

\subsection{Histórico e estruturação do Núcleo de Inovação Tecnológica da UEPB}

Impulsionada pela promulgação da Lei de Inovação, que determinou a criação do Núcleo de Inovação Tecnológica em toda ICT pública ou privada e buscando incentivar a inovação e a pesquisa científica e tecnológica no ambiente produtivo, a Universidade Estadual da Paraíba (UEPB) criou, em março de 2009, o Núcleo de Inovação e Transferência Tecnológica - NITT/UEPB.

Quanto à sua formalização, verificou-se que a intenção inicial foi a de participar do edital de criação da Rede de Núcleos de Inovação, lançado pelo Conselho Nacional de Desenvolvimento Científico e Tecnológico - CNPq, no ano de 2008. Nesse intuito, foi elaborado um projeto que envolvia a participação de 10 instituições da Paraíba, a saber: UFCG, UEPB, IFPB, INSA, PAQTcPB, FIEP, SEBRAE, SENAI, EMBRAPA, UFPB. Porém, o projeto do NITT/UEPB não foi contemplado no referido edital. Assim, o NITT/UEPB foi formado sem apoio externo, apenas com apoio institucional da Reitoria e da Pró-Reitoria de Pós-Graduação e Pesquisa - PRPGP da UEPB.

Foi através da Resolução UEPB/CONSUNI/029 /2008, assinada em 24 de outubro de 2008 e publicada em 27 de março de 2009, que o Núcleo de Inovação e Transferência Tecnológica - NITT foi instituído dentro da UEPB (UEPB/CONSUNI, 2008).

Antes da criação do Núcleo de Inovação e Transferência Tecnológica, a UEPB não possuía nenhum outro setor voltado especificamente para a gestão da inovação. Sendo assim, sob a perspectiva de que cabia à Pró-Reitoria de Pós-Graduação e Pesquisa fomentar a pesquisa na UEPB, o NITT/UEPB foi criado inicialmente vinculado à PRPGP. Nessa fase, as atribuições do NITT/UEPB limitavam-se basicamente à disseminação da cultura da propriedade intelectual na instituição. Sua principal atribuição era mobilizar e orientar os pesquisadores nos procedimentos relativos à proteção e difusão de suas invenções.

No ano de 2015, compreendendo a importância estratégica do NITT, com aprovação do Conselho Universitário (CONSUNI), o NITT-UEPB passou a se chamar Agência de Inovação Tecnológica da UEPB - INOVATEC/UEPB, e comporia órgão suplementar diretamente vinculado à Reitoria com suas atribuições definidas em regimento próprio. Essa alteração foi publicada através da Resolução/UEPB/CONSUNI/0143/2015, que também discorre sobre o regimento da Inovatec (UEPB/CONSUNI, 2015). A referida resolução amplia o campo de atuação da Inovatec e apresenta como sua missão não apenas as atividades ligadas diretamente à propriedade intelectual, mas também agrega as iniciativas relacionadas ao 
empreendedorismo, a promoção do ambiente de negócios relacionados à inovação tecnológica, dentre outros serviços tecnológicos.

Ainda em relação a sua formalização, foi possível observar que a Inovatec passou por outra reestruturação. Dessa vez, a alteração foi em relação à nomenclatura de seus cargos para se adequar ao estatuto da UEPB. Então, em 2020, através da RESOLUÇÃO/UEPB/CONSUNI/0326/2020, a Agência de Inovação Tecnológica da UEPB INOVATEC/UEPB passou a ser Coordenadoria Inovação Tecnológica da UEPB INOVATEC/UEPB. Logo, onde antes havia cargo de diretores, passou a ser chamado de coordenador (UEPB/CONSUNI, 2020). Assim com a finalidade de desempenhar todas as atividades estabelecidas nas resoluções, a Inovatec foi reestruturada de acordo com o seguinte organograma (figura 1):

\section{Figura 1.}

Organograma da Inovatec

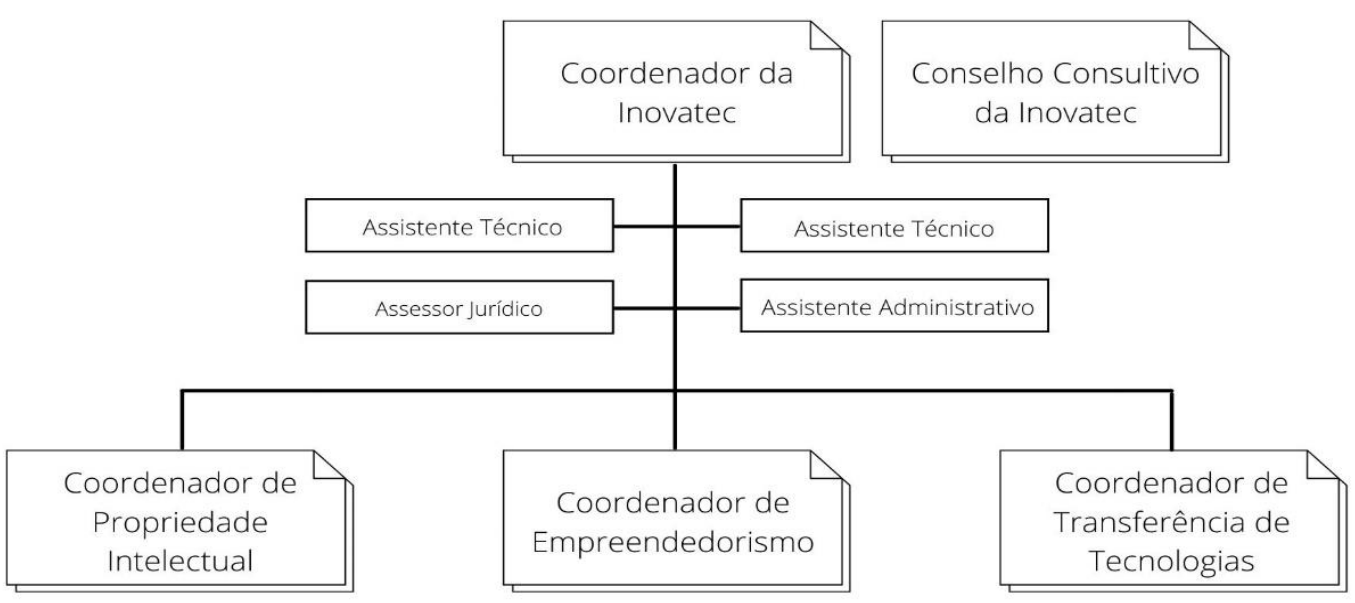

Fonte: Elaborada pelas autoras, 2021.

Assim, neste contexto, a Inovatec é uma coordenadoria vinculada diretamente à Reitoria da instituição, sendo composta por uma coordenadoria executiva, onde cada coordenador é responsável por uma área de atuação.

O coordenador de propriedade intelectual é responsável pela manutenção dos títulos de propriedade intelectual da instituição, pela abertura e acompanhamento de processos de licenciamento e demais questões referentes à propriedade intelectual. O coordenador de transferência de tecnologias é responsável por promover parcerias entre universidade e empresas para atuarem no desenvolvimento de produtos e processos inovadores, licenciamento e transferências de conhecimentos e invenções protegidas pela universidade. E o coordenador 
de empreendedorismo é responsável por desenvolver atividades que promovam a educação e a formação empreendedora na UEPB, além de estruturar e apoiar a formação de incubadoras de empresas de base tecnológica surgidas das criações protegidas e mantidas pela UEPB.

Observou-se ainda que, conforme estabelecido na resolução 0326/2020, a direção da Inovatec fica a cargo do coordenador de propriedade intelectual, assessorado pelo coordenador de empreendedorismo e o coordenador de transferência de tecnologia. Além disso, existe o Conselho Consultivo, órgão que atua de maneira conjunta e paralela à Inovatec. Este é formado pela representação indicada por cada Centro acadêmico da instituição e se reúne periodicamente para opinar, avaliar, analisar e auxiliar nas tomadas de decisões inerentes às atividades da Inovatec.

Nas questões relacionadas ao quadro de pessoal da Inovatec, foi possível averiguar que, ao longo dos anos, ocorreram poucas mudanças no número de colaboradores da equipe da Inovatec. Desde sua criação até o ano de 2017, a equipe da Inovatec foi composta apenas pelos coordenadores e um assistente técnico, além de um estagiário por semestre, que devido à natureza do "cargo" tinha prazo de permanência determinado na Inovatec. Assim, efetivamente, a equipe, por muito tempo, foi composta por apenas 4 (quatro) pessoas.

A partir do ano de 2018, a equipe da Inovatec começa a ganhar novos integrantes. Após concurso público realizado pela universidade, em abril de 2018, uma nova assistente técnica foi integrada à equipe. E, em março de 2021, mais dois novos servidores foram incluídos no grupo de trabalho, totalizando sete pessoas trabalhando na equipe. No ano de 2021, a Inovatec teve alocada à sua equipe uma bolsista PNPD (Programa Nacional de Pós Doutorado), sendo a bolsa financiada pela Fundação de Apoio do Estado da Paraíba- FAPESQ, com estratégia para desenvolvimento de atividades de pesquisa junto com a Inovatec na criação do Observatório Tecnológico da UEPB.

Vale ressaltar que das sete pessoas que compõem a Inovatec, apenas três têm dedicação exclusiva para o setor, isto porque os demais membros exercem outras atividades na universidade, tanto em sala de aula, lecionando, como em outras funções de direção e chefia. Essa é uma situação vivenciada por outros NIT's, que, conforme apresentados pelos autores Quintella, Almeida, Santos, Torkomian \& Santos (2018), muitas vezes são gerenciados e administrados por professores parcialmente deslocados de suas atividades acadêmicas usuais.

Quanto à regulamentação interna da universidade acerca das questões de inovação, foi possível identificar algumas legislações internas. Em primeiro lugar, foi identificada a existência da Política de Inovação da UEPB, aprovada pelo Consuni em 2017, através da Resolução/UEPB/CONSUNI/0215/2017. Esta resolução regula, no âmbito da UEPB, as 
atividades de inovação, propriedade intelectual, transferência e licenciamento de tecnologia e incubação de empresas tecnológicas (UEPB/CONSUNI, 2017).

Além da Política de Inovação, foi possível identificar ainda a resolução 0233/2018, que trata do Programa de Incubação de Empresas da Universidade (UEPB/CONSUNI, 2018a) e a resolução 0250/2018, que regula a criação e o funcionamento das Empresas Juniores no âmbito da UEPB (UEPB/CONSUNI, 2018b), sendo todas estas resoluções vinculadas à Inovatec.

\subsection{Gestão e perfil institucional do Núcleo de Inovação Tecnológica da UEPB}

Em relação aos resultados da gestão da Inovatec, foi possível identificar alguns números importantes. Os números apresentados, na figura 2, demonstram quantitativamente os resultados do trabalho que vem sendo executado ao longo dos anos pela Inovatec. Notou-se um crescimento na produção da Inovatec a partir do ano de 2019, este aumento pode estar relacionado ao fato de que, apesar do Marco Legal ter sido promulgado em 2016, o seu decreto regulamentador $\left(\mathrm{n}^{\circ}\right.$ 9.283) só foi publicado em 2018, assim a regulamentação da Lei pode ter influenciado na desburocratização das atividades de pesquisa e inovação na instituição.

\section{Figura 2.}

Resultados da Gestão da Inovatec de 2009 a 2021

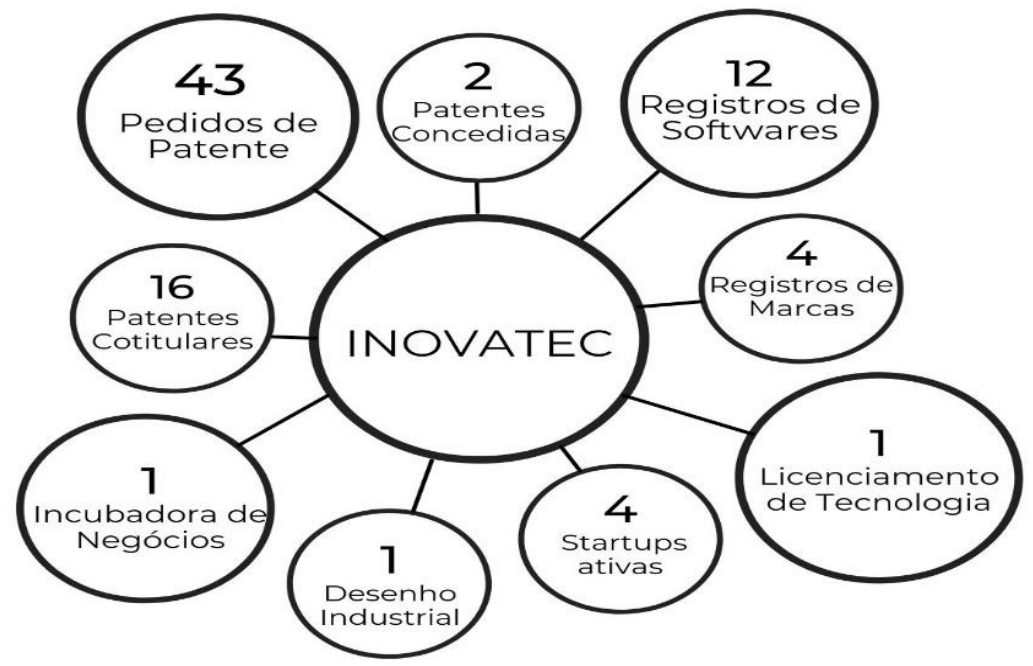

Fonte: Elaborada pelas autoras, 2021.

A figura 2 evidencia números relevantes no que tange aos resultados da gestão da inovação na UEPB, no entanto, esses números ainda são pouco expressivos, principalmente se compararmos com os números de outros NIT's. É possível observar que dentre os 59 pedidos de patente solicitados, existe apenas 1(um) licenciamento. Essa discrepância entre o que está 
protegido e o que está disponível para a sociedade pode ser um sinal de alerta para um melhoramento da gestão da transferência de tecnologia na instituição. Em contrapartida, podese observar que a universidade possui 4 startups em funcionamento que podem, inclusive, ter tecnologias protegidas. A criação de startups dentro da universidade demonstra um bom desenvolvimento do empreendedorismo universitário.

Em relação à atuação da Inovatec, no sentido de promoção da inovação na instituição, foi observado que um dos grandes desafios que a Inovatec enfrenta está relacionado à abrangência da universidade, por ser uma instituição multicampi, com 8 campis distribuídos por toda a região do Estado da Paraíba. Isso dificulta a tarefa de agregar e envolver toda a comunidade acadêmica nas iniciativas de inovação. Para contornar esse obstáculo, a Inovatec conta com o auxílio do Conselho Consultivo, que tem representação de cada centro acadêmico e também com o diferencial de ter, na sua equipe, coordenadores e colaboradores alocados em diversos campis.

Foi possível perceber que as dificuldades de gestão encontradas na Inovatec são dificuldades comuns a outros NIT's do Brasil. A escassez de recursos humanos especializados, por exemplo, é um problema enfrentado por vários NIT's no país, e é também um obstáculo para o desenvolvimento das atividades da Inovatec. Além disso, notou-se que a Inovatec esbarra, muitas vezes, nas barreiras da burocracia para desenvolver suas atividades. Os processos que deveriam ser executados de forma célere, tendo em vista tratarem de inovação tecnológica, deparam-se com a falta de flexibilidade operacional, causando ineficiência no seu processo de gestão.

Entretanto, apesar das dificuldades encontradas, foi possível observar que a Inovatec atua em todas as atividades descritas no Art. 16 da Lei 13.243/16, a saber:

I - zelar pela manutenção da política institucional de estímulo à proteção das criações, licenciamento, inovação e outras formas de transferência de tecnologia; II - avaliar e classificar os resultados decorrentes de atividades e projetos de pesquisa para o atendimento das disposições desta Lei; III - avaliar solicitação de inventor independente para adoção de invenção na forma do art. 22; IV - opinar pela conveniência e promover a proteção das criações desenvolvidas na instituição; V - opinar quanto à conveniência de divulgação das criações desenvolvidas na instituição, passíveis de proteção intelectual; VI - acompanhar o processamento dos pedidos e a manutenção dos títulos de propriedade intelectual da instituição; VII - desenvolver estudos de prospecção tecnológica e de inteligência competitiva no campo da propriedade intelectual, de forma a orientar as ações de inovação da ICT; VIII - desenvolver estudos e estratégias para a transferência de inovação gerada pela ICT; IVpromover e acompanhar o relacionamento da ICT com empresas, em especial para as atividades previstas nos arts. $6^{\circ}$ a $9^{\circ} ; \mathbf{X}$ - negociar e gerir os acordos de transferência de tecnologia oriunda da ICT (BRASIL, 2016, grifos nossos).

O estudo dos documentos e legislações da instituição e também a experiência vivida pelas autoras desse artigo, na Inovatec, permitiram constatar que foi a Resolução 143/2015 que 
propiciou uma atuação mais abrangente por parte da Inovatec, englobando, assim, todas as atribuições relacionadas ao Marco Legal da Ciência Tecnologia e Inovação.

Foi constatado que a coordenadoria de propriedade intelectual é o setor dentro da Inovatec que opera as atribuições relacionadas do item I ao VII do Art. 16 do Marco Legal da Ciência Tecnologia e Inovação. Enquanto que a coordenadoria de transferência de tecnologias atua nos itens VIII, IX e X deste mesmo artigo. Além disso, a Inovatec também desempenha atividades relacionadas a negócios, através da coordenadoria de empreendedorismo.

De acordo com Lotufo (2009), o NIT pode ser caracterizado em três perfis em função de suas atividades, o perfil legal, o perfil administrativo e o perfil de negócios. Partindo dessa visão de Lotufo (2009), foi possível identificar que a Inovatec atua nesses três eixos. Essa atuação legal, administrativa e de negócios tornou-se possível graças às alterações feitas pela resolução 143/2015, que conseguiu compreender todas as funções estabelecidas na lei 13.243/2016. Além disso, pode-se destacar o desempenho de cada coordenadoria que opera, de forma independente, em cada uma de suas atribuições, mas também trabalha em conjunto para o fortalecimento da Inovatec e da UEPB como um todo.

Lotufo (2009) também caracteriza o NIT, de acordo com suas missões, em três categorias:

[...] os que enfatizam a busca de royalties como fonte extra de recursos para a universidade; os que buscam maximizar o desenvolvimento regional a partir da transferência de tecnologia, especialmente por meio da formação de empresas spin-off; e os que buscam maximizar o benefício à sociedade em geral a partir dos resultados da pesquisa acadêmica [...] (Lotufo, 2009).

Nesse sentido, infere-se que a Inovatec tem uma parcela de cada uma dessas missões, pois conforme descrito em sua página oficial, a Inovatec tem como missão "promover atividades de estímulo à inovação e ao empreendedorismo na UEPB, ampliando o impacto do ensino, da pesquisa e da extensão em favor do desenvolvimento socioeconômico da região".

Assim, foi possível constatar que as resoluções da universidade atendem às competências definidas no Novo Marco Legal da Ciência, Tecnologia e Inovação. No entanto, vale ressaltar que a falta de flexibilidade operacional e a escassez de recursos humanos capacitados causam um atraso significativo nos processos da Inovatec.

A Inovatec vem buscando alternativas para dirimir essas questões, como, por exemplo, a criação de um observatório tecnológico para mapear as tecnologias em fase inicial de desenvolvimento. A criação desse observatório permitirá que, de forma mais rápida, possa ser identificado o que está sendo produzido na universidade, a fim de agilizar o processo de proteção dessas tecnologias e disponibilização delas ao mercado. 
Por fim, é importante apontar que a Inovatec vem conseguindo superar suas limitações e atingindo com excelência aquilo que propõe sua missão. Porém, ainda há muito trabalho a ser realizado para que essas competências sejam mais relevantes e possam contribuir mais efetivamente com desenvolvimento socioeconômico da região.

\section{Considerações finais}

Este relato técnico apresentou uma descrição acerca da gestão da inovação do Núcleo de Inovação Tecnológica da UEPB. O foco da pesquisa foi descrever as atividades realizadas pelo Núcleo de Inovação Tecnológica da UEPB, identificando seu perfil institucional com base no Novo Marco Legal da Ciência, Tecnologia e Inovação (Lei no 13.243/2016), para contribuir para estruturação de outros NITs estaduais.

Assim, após análise dos documentos, constatou-se que o NIT da UEPB atua em todas as funções estabelecidas no Novo Marco Legal da Ciência, Tecnologia e Inovação e, em relação a sua missão, foi verificado que o NIT da UEPB procura beneficiar tanto sua instituição como a sociedade, ao mesmo tempo em que incentiva o desenvolvimento regional.

Dessa forma, de acordo com suas funções, há momentos que o NIT da UEPB se revela com um perfil mais administrativo, em outros, assume o perfil legal e, em outros momentos, assume o perfil de negócios. Assim, na prática, o NIT UEPB contém uma parcela das três categorias. É importante ressaltar que mesmo atuando nos três perfis, a atuação do NIT da UEPB é bastante modesta. Esse moderado desempenho se deve, principalmente, às limitações operacionais (recursos humanos e financeiros) enfrentadas pelo NIT da UEPB. Foi verificado também que algumas estratégias estão sendo adotadas na tentativa de ultrapassar esses limitadores.

O estudo da gestão do NIT da UEPB revelou a importância de agregar conhecimentos multidisciplinares para uma atuação mais efetiva e eficaz na gestão da inovação. A Inovatec tem empreendido esforços na divulgação da cultura da propriedade intelectual, no apoio de projetos que podem se concretizar em um ativo passível de transferência de tecnologia ou ainda na criação de startups que possam comercializá esse ativo.

Em resumo, os esforços do NIT da UEPB têm contribuído para o engajamento da comunidade acadêmica em atividades voltadas ao desenvolvimento tecnológico, à inovação e ao empreendedorismo. Sugere-se que futuros estudos sejam realizados a fim de analisarem o perfil de atuação do NIT de outras instituições, tendo em vista as disparidades significativas existente entre as ICT brasileiras. 


\section{Referências}

Brasil. Lei no 10.973, de 2 de dezembro de 2004. (2004). Dispõe sobre incentivos à inovação e à pesquisa científica e tecnológica no ambiente produtivo e dá outras providências. Diário Oficial da União. Brasília, DF. Disponível em: http://www.planalto.gov.br/ccivil_03/_Ato2004-2006/2004/Lei/L10.973.htm. Acesso em: 20 mai 2021.

Brasil. Lei $\mathrm{n}^{\circ}$ 13.243, de janeiro de 2016. (2016). Dispõe sobre estímulos ao desenvolvimento científico, à pesquisa, à capacitação científica e tecnológica e à inovação e altera outras leis. Diário Oficial da União. Brasília, DF. Disponível em: http://www.planalto.gov.br/ccivil_03/_ato2015-2018/2016/lei/113243.htm. Acesso em: 20 mai 2021.

Brasil. Decreto $n^{\circ}$ 9.283, de 07 de fevereiro de 2018. (2018). Dispõe sobre medidas de incentivo à inovação e à pesquisa científica e tecnológica no ambiente produtivo, com vistas à capacitação tecnológica, ao alcance da autonomia tecnológica e ao desenvolvimento do sistema produtivo nacional e regional. Diário Oficial da União. Brasília, DF. Disponível em: http://www.planalto.gov.br/ccivil_03/_ato20152018/2018/decreto/d9283.htm. Acesso em: 20 mai 2021.

Brasil. Política de propriedade intelectual das instituições científicas e tecnológicas do Brasil. (2019). Relatório FORMICT 2018. Brasília, DF: Ministério da Ciência, Tecnologia e Inovação - MCTI, 2019.

CNI. (2010). Cartilha: gestão da inovação. Brasília: CNI, MEI, 2010.

Ferreira, R. S. S. G. (2018). Direito e Inovação: o novo Marco Legal de Ciência, Tecnologia e Inovação e a personalidade jurídica para os Núcleos de Inovação Tecnológica. (Dissertação de Mestrado), Universidade Federal de Minas Gerais, Belo Horizonte, MG, Brasil.

Gavira, M. D. O., Ferro, A. F. P., Rohrich, S. S., \& Quadros, R. (2007). Gestão da inovação tecnológica: uma análise da aplicação do funil de inovação em uma organização de bens de consumo. Revista de administração Mackenzie, 8(1), 77-107.

Lima, R. F. P., \& Sartori, R. (2020). A Relação entre Universidade e Empresa Mediada pelos Núcleos de Inovação Tecnológica: Um Estudo na UTFPR. Navus: Revista de Gestão e Tecnologia, 10(1), 1-15. Disponível em: http://navus.sc.senac.br/index.php/navus/article/view/1433. Acesso em: 15 mai 2021

Lopes, E. G. L. G., Teles, E. O., Silva, M. S., \& Lopes, J. M. (2020). Indicadores de Inovação Aberta: Uma proposta em consonância com o Marco de Inovação para ICTS. VI ENPI-Encontro Nacional de Propriedade Intelectual, Natal, RN, Brasil, 6.

Lotufo, R. A. (2009). A institucionalização de Núcleos de Inovação Tecnológica e a experiência da Inova Unicamp. Transferência de Tecnologia: estratégias para estruturação e gestão dos Núcleos de Inovação Tecnológica. Campinas: Komedi, 4174. 
Melo, D. F., Rita, L. P. S, Ferreira, R. R. F., Jr, Tonholo, J., \& Oliveira Sá, E. M. (2020). Políticas públicas para inovação: um estudo da metodologia de gestão da inovação na indústria em Alagoas. Navus: Revista de Gestão e Tecnologia, 10(1), 1-20.

Pires, M. C. F. S., Rita, L. P. S., \& Pires, A. C. S. (2020). Perfil do núcleo de inovação tecnológica na gestão da inovação: um estudo na Universidade Federal de Alagoas. Navus: Revista de Gestão e Tecnologia, 10(1), 1-16. Disponível em: http://navus.sc.senac.br/index.php/navus/article/view/1000. Acesso em: 15 mai 2021.

Quintella, C. M., Almeida, B. A., Santos, W. P. C., Torkomian, A. L. V. \& Santos, P. J. R. (2018). Gestão de Inovação Tecnológica baseada em Propriedade Intelectual. Políticas Públicas de CT\&I e o Estado Brasileiro (Vol. I). Bahia: IFBA, 59-129.

Quintella, C. M. \& Torres, E. A. (2012). Gestão e Comercialização de Tecnologia. Capacitação em Inovação Tecnológica para Empresários (Vol. 2). São Cristóvão: Editora UFS, 185-200.

Rauen, C. V. (2016). O novo marco legal da inovação no Brasil: o que muda na relação ICTEmpresa? Repositório do Conhecimento do IPEA. Disponível em: http://repositorio.ipea.gov.br/handle/11058/6051. Acesso em: 15 mai 2021

Tidd, J., Bessant, J., \& Pavitt, Keith (2015). Gestão da inovação-5. Porto Alegre. Bookman.

Toledo, P. T. M. (2015). A gestão da inovação em universidades: evolução, modelos e propostas para instituições brasileiras. (Tese de Doutorado), Universidade Estadual de Campinas, Campinas, SP, Brasil.

UEPB/CONSUNI. Resolução/UEPB/CONSUNI n 029, de 24 de outubro de 2008. (2008). Cria o Núcleo de Inovação e Transferência Tecnológica e dá outras providências. Paraíba. Disponível em: http://nucleos.uepb.edu.br/inovatec/download/resolucaouepbconsuni0292008/. Acesso em: 17 mai 2021.

UEPB/CONSUNI. Resolução/UEPB/CONSUNI nº 143, de 30 de novembro de 2015. (2015). Cria a Agência de Inovação Tecnológica da UEPB - INOVATEC UEPB, e dá outras providências. Paraíba. Disponível em:

http://nucleos.uepb.edu.br/inovatec/download/resolucao-uepb-consuni-0143-2015transforma-o-nitt-em-inovatec-inclui-o-regimento/. Acesso em: 17 mai 2021.

UEPB/CONSUNI. Resolução/UEPB/CONSUNI n 215, de 01 de dezembro de 2017. (2017). Aprova a Política de Inovação da Universidade Estadual da Paraíba e dá outras providências. Paraíba. Disponível em:

http://transparencia.uepb.edu.br/download/0215-2017-politica-de-inovacao-da-uepb/. Acesso em: 17 mai 2021.

UEPB/CONSUNI. Resolução/UEPB/CONSUNI nº 233, de 17 de maio de 2018. (2018a). Aprova o Programa de Incubação de Empresas da Universidade Estadual da Paraíba UEPB e dispõe sobre o seu funcionamento. Paraíba. Disponível em: http://transparencia.uepb.edu.br/download/0233-2018-aprova-o-programa-deincubacao-de-empresas-da-uepb/. Acesso em: 17 mai 2021. 
UEPB/CONSUNI. Resolução/UEPB/CONSUNI n 250, de 13 de agosto de 2018. (2018b). Regulamenta a criação e funcionamento das Empresas Juniores no âmbito da UEPB. Paraíba. Disponível em: http://transparencia.uepb.edu.br/download/0250-2018regulamenta-a-criacao-das-empresas-juniores/. Acesso em: 17 mai 2021.

UEPB/CONSUNI. Resolução/UEPB/CONSUNI n 326, de 15 de junho de 2020. (2020). Altera a redação de artigos do Regimento da INOVATEC/UEPB, redefine nomenclatura dos cargos e dá outras providências. Paraíba. Disponível em: http://transparencia.uepb.edu.br/download/resolucao-consuni-0326-2020-aprovaalteracoes-no-regimento-interno-da-inovatec/. Acesso em: 17 mai 2021.

Velho, S. R. K., Campagnolo, J. M, \& Dubeux, R. R. (2019). O regulamento do novo marco legal da inovação. Parcerias Estratégicas, 24(48), 83-102. Disponível em: http://seer.cgee.org.br/index.php/parcerias_estrategicas/issue/view/88/showToc Acesso em: 17 mai 2021. 